\title{
North Macedonia
}

National Cancer Institute

\section{Source}

National Cancer Institute. North Macedonia. NCI Thesaurus. Code C17654.

A country in southeastern Europe, north of Greece, between Albania and Bulgaria. 